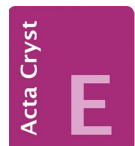

CRYSTALLOGRAPHIC COMMUNICATIONS

ISSN 2056-9890

Received 21 June 2019

Accepted 26 July 2019

Edited by A. Van der Lee, Université de Montpellier II, France

Keywords: cadmium germanium arsenide; crystal structure; XRD; EBSD.

CCDC reference: 1943551

Supporting information: this article has supporting information at journals.iucr.org/e

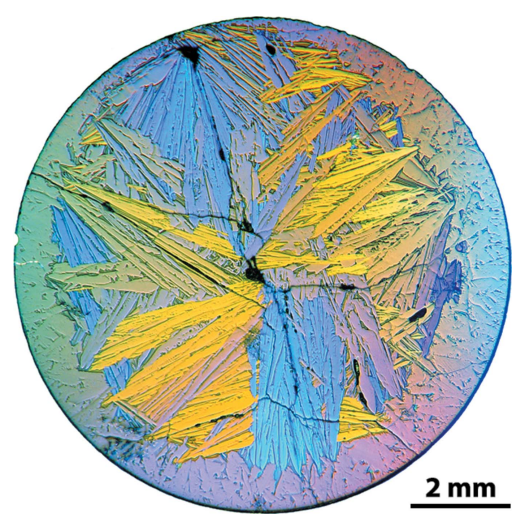

OPEN $\odot$ ACCESS

\section{Crystal structure and chemistry of tricadmium digermanium tetraarsenide, $\mathrm{Cd}_{3} \mathrm{Ge}_{2} \mathrm{As}_{4}$}

Michael R. Thompson, Brian J. Riley,* Mark E. Bowden, Matthew J. Olszta, Danny J. Edwards, Jarrod V. Crum, Bradley R. Johnson and Saehwa Chong

Pacific Northwest National Laboratory, Richland, WA 99354, USA. *Correspondence e-mail: brian.riley@pnnl.gov

A cadmium germanium arsenide compound, $\mathrm{Cd}_{3} \mathrm{Ge}_{2} \mathrm{As}_{4}$, was synthesized using a double-containment fused quartz ampoule method within a rocking furnace and a melt-quench technique. The crystal structure was determined from singlecrystal X-ray diffraction (SC-XRD), scanning and transmission electron microscopies (i.e. SEM, STEM, and TEM), and selected area diffraction (SAD) and confirmed with electron backscatter diffraction (EBSD). The chemistry was verified with electron energy loss spectroscopy (EELS).

\section{Chemical context}

Crystalline $A^{\mathrm{II}} B^{\mathrm{IV}} C_{2} \mathrm{~V}$ chalcopyrites such as $\mathrm{CdGeAs}_{2}$ are often studied for their non-linear optical properties (Boyd et al., 1972; Byer, 1975; Byer et al., 1971) amongst other promising applications. However, growing these materials in large volumes has proven difficult because of anisotropic thermal expansion that occurs during cooling (Iseler et al., 1978; Boyd et al., 1972; Schunemann \& Pollak, 1998; Shay \& Wernick, 1975; Kildal, 1972). During phase-diagram studies (Borshchevskii et al., 1967; Borshchevskii \& Roenkov, 1969) as well as crystal growth and syntheses efforts to produce amorphous Cd-Ge-As compounds (Hong et al., 1990; Mikkelsen Jr \& Hong, 1974; Pamplin \& Feigelson, 1979; Sharma et al., 1989; Zawilski et al., 2008), several different CdGe-As impurity phases were observed in addition to the target $\mathrm{CdGeAs}_{2}$ compound. These include $\mathrm{Cd}_{7} \mathrm{Ge}_{91} \mathrm{As}_{2}$ (Hong et al., 1990), $\mathrm{Cd}_{13} \mathrm{Ge}_{81} \mathrm{As}_{6}$ (Hong et al., 1990), $\mathrm{Cd}_{28} \mathrm{Ge}_{7} \mathrm{As}_{65}$ (Hong et al., 1990), $\mathrm{Cd}_{29} \mathrm{Ge}_{14} \mathrm{As}_{57}$ (Mikkelsen Jr \& Hong, 1974), $\mathrm{Cd}_{33} \mathrm{Ge}_{11} \mathrm{As}_{56}$ (Hong et al., 1990), and $\mathrm{Cd}_{33} \mathrm{Ge}_{25} \mathrm{As}_{42}$ (Pamplin \& Feigelson, 1979). During separate experiments by the authors where $\mathrm{CdGeAs}_{2}$ materials were being synthesized for amorphous radiation detectors (Johnson et al., 2009), a phase with the composition of $\sim \mathrm{Cd}_{33} \mathrm{Ge}_{22} \mathrm{As}_{45}$ (or $\mathrm{Cd}_{3} \mathrm{Ge}_{2} \mathrm{As}_{4}$ ) was observed. This phase was not observed during any of the studies previously reported in the literature (Hong et al., 1990; Mikkelsen Jr \& Hong, 1974; Pamplin \& Feigelson, 1979; Sharma et al., 1989; Zawilski et al., 2008; Schunemann \& Pollak, 1998; Speyer et al., 1989), and the formation of this crystalline phase is thought to be due to the unique double-containment ampoule method used during synthesis.

In our previous paper (Riley et al., 2012), we described the synthesis process for maximizing the production of the $\mathrm{Cd}_{3} \mathrm{Ge}_{2} \mathrm{As}_{4}$ crystalline phase where the target composition was batched and processed under similar conditions used for making $\mathrm{CdGeAs}_{2}$, including the double-containment ampoule 

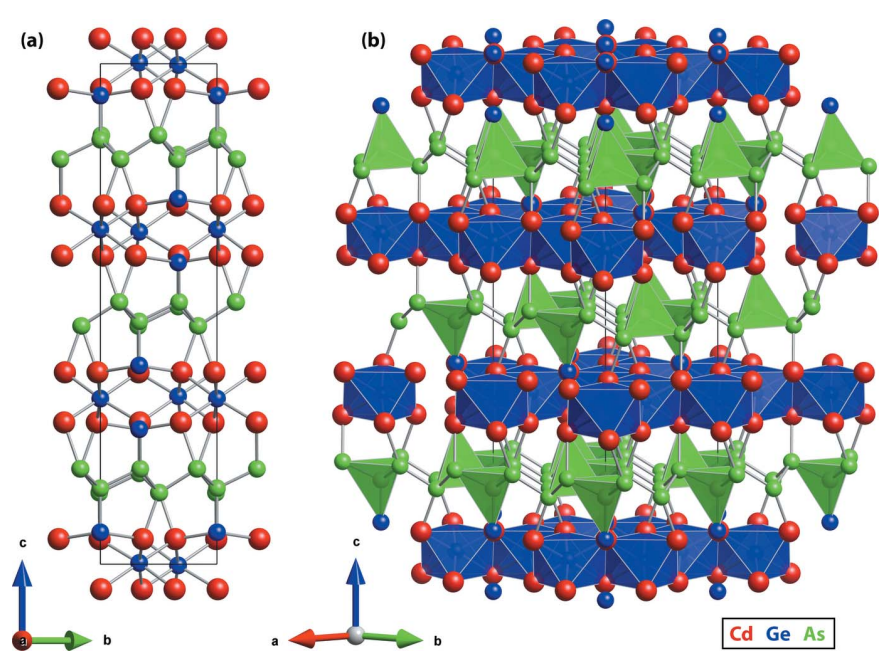

Figure 1

Crystal structure of the $\mathrm{Cd}_{3} \mathrm{Ge}_{2} \mathrm{As}_{4}$ showing (a) the distribution and linkages of atoms and $(b)$ the layer structure composed of $\mathrm{GeAs}_{4}$ tetrahedra and $\mathrm{GeCd}_{6}$ octahedra; the legend is shown in the bottom right $(\mathrm{Cd}=\mathrm{red}, \mathrm{Ge}=$ blue, $\mathrm{As}=$ green $)$. The reader is referred to the online version for reference to color.

method. In this paper, we report the crystal structure of the $\mathrm{Cd}_{3} \mathrm{Ge}_{2} \mathrm{As}_{4}$ crystalline phase; using XRD and analytical electron microscopies, it was shown to belong to the trigonal system in the $R \overline{3}$ space group (No. 148). The SC-XRD analysis of small shards of the crystalline phase were utilized to propose the atomic positions of each of the elements, and subsequent use of a double-tilt stage holder in (S)TEM coupled with EELS analysis confirmed these data. Through the combination of these two techniques, the structure of this newly formed phase could be accurately described. Using the crystallographic information file (CIF) created with SC-XRD, EBSD was used to demonstrate successful pattern indexing from the Kikuchi patterns.

\section{Structural commentary}

The SC-XRD data yielded a trigonal unit cell of space group $R \overline{3}$ (No. 148) with lattice parameters $a, b=7.3748$ (13) $\AA$ and $c$ = 27.415 (5) $\AA$ (see Table 1). The heavy-scattering Cd atom was assigned to a general position $c a 1.4 \AA$ above the $a b$ plane with some confidence, but $\mathrm{Ge}$ and As have similar scattering factors and were distributed amongst the remaining sites with less certainty. The lowest $R$ factor (3.62\% for all data) was
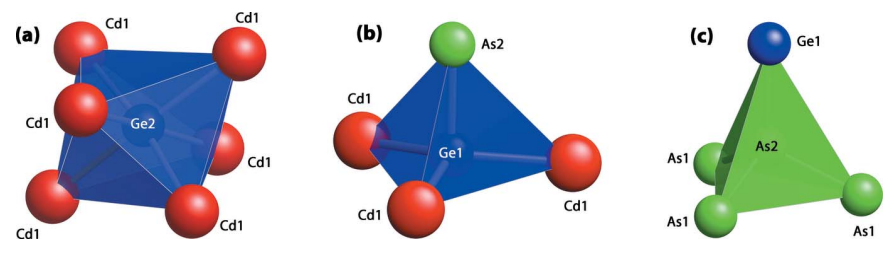

Figure 2

Coordinated atoms around $\mathrm{Ge} 2, \mathrm{Ge} 1$, and As2 are shown as (a) a Ge2(Cd1 $)_{6}$ octahedron, $(b)$ a $\mathrm{Ge} 1\left[(\mathrm{Cd} 1)_{3} \mathrm{As} 2\right]$ tetrahedron, and $(c)$ an As2 $\left[(\mathrm{As} 1)_{3} \mathrm{Ge} 1\right]$ tetrahedron. found for the final refinement of the atomic poisitions, which also agreed with the expected stoichiometry of $\mathrm{Cd}_{3} \mathrm{Ge}_{2} \mathrm{As}_{4}$. The structure is shown in Fig. 1 and contains sheets of metal atoms stacked along the $c$ axis. The $\mathrm{Cd}$ site and both As sites are tetrahedrally coordinated to neighboring metal atoms. The two Ge sites have tetrahedral (to three $\mathrm{Cd}$ and one $\mathrm{As}$ ) and octahedral (to six Cd) coordination environments, respectively (see Fig. 2). Having Ge in these two environments is consistent with the expected valences of the metal atoms. If $\mathrm{Cd}$ and $\mathrm{As}$ are assigned their expected oxidation states of $\mathrm{Cd}^{2+}$ and $\mathrm{As}^{3-}$, respectively, then one $\mathrm{Ge}^{2+}$ and one $\mathrm{Ge}^{4+}$ are required for charge neutrality.

\section{Synthesis and characterization}

The $\mathrm{Cd}_{3} \mathrm{Ge}_{2} \mathrm{As}_{4}$ sample, made using a double-containment quartz ampoule setup (see Fig. 3a), is discussed elsewhere in more detail (Johnson et al., 2009; Riley et al., 2012), but will be briefly described here. For the double-containment ampoule setup, high purity Cd (4.4916 g, 99.9999\%), Ge (2.9030 g, 99.9999\%), and As (5.9907 g, 99.99999+\%) (Alfa Aesar, Ward Hill, MA) were added into a pre-cleaned fused quartz vessel [10×12 mm; GE214, GM Associates, Inc., Oakland, CA; cleaning details are provided elsewhere (Riley et al., 2012)] while inside a nitrogen glovebox $\left(<0.1 \mathrm{ppm}\right.$ of $\mathrm{O}_{2} / \mathrm{H}_{2} \mathrm{O}$; M-Braun, Inc., Stratham, NH). Then, the vessel was moved out of the glovebox while connected to a sealed gate valve and 12.5-mm compression fitting to make sure that the contents of

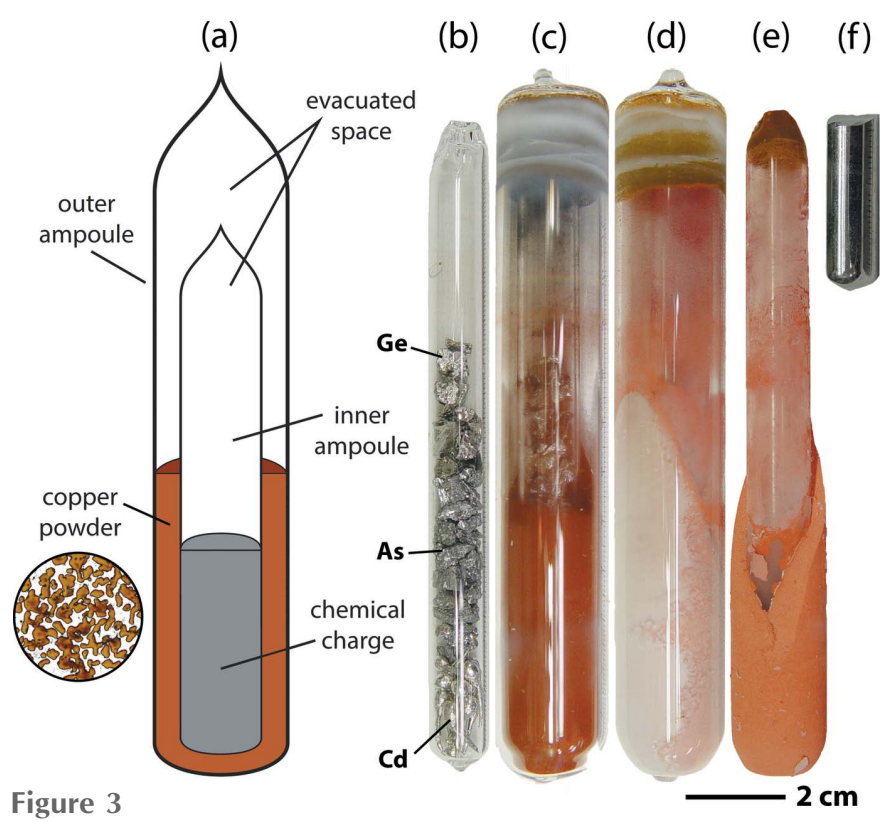

(a) Schematic of double-containment ampoule setup showing a high magnification of the sintered copper powder. $(b-f)$ Progression of steps involved in the double-containment ampoule process [with scalebar for $(b)-(f)]$ showing $(b)$ elements packed in an evacuated and sealed $10 \times 12 \mathrm{~mm}$ inner FQ tube, $(c)$ the inner ampoule loaded into an evacuated and sealed outer $19 \times 22 \mathrm{~mm}$ FQ tube containing copper powder, $(d)$ the assembly after heat treatment, $(e)$ the assembly removed from the outer ampoule, and $(f)$ the ingot removed from the inner ampoule. This figure was recreated with permission from the American Ceramic Society. 
the ampoule were not exposed to the atmosphere. Then, the ampoule was evacuated, purged with semiconductor grade $\mathrm{Ar} /$ $2.6 \% \mathrm{H}_{2}$ to $1.6 \times 10^{4} \mathrm{~Pa}$ (120 Torr), and sealed with an oxypropane torch. This is the inner ampoule shown in Fig. $3 b$. This inner ampoule was loaded into a $19 \times 22 \mathrm{~mm}$ fused quartz tube (outer ampoule, Fig. $3 c, d$ ) that was sealed at the base, and the annulus between the two vessels was filled with $17.8 \mathrm{~g}$ of $\mathrm{Cu}$ powder $(\leq 75 \mu \mathrm{m})$. The ampoule was heat treated in a rocking furnace where it was ramped at $3{ }^{\circ} \mathrm{C} \mathrm{min}^{-1}$ from room temperature to $400^{\circ} \mathrm{C}$, held for $2 \mathrm{~h}$ in a fixed position, ramped to $625^{\circ} \mathrm{C}$ at $3^{\circ} \mathrm{C} \mathrm{min}^{-1}$, held for $2 \mathrm{~h}$, ramped to $850^{\circ} \mathrm{C}$ at $3^{\circ} \mathrm{C}$ $\min ^{-1}$, held for $25 \mathrm{~h}$, rocking was paused for $10 \mathrm{~min}$ to allow the melt to settle to the base, and then the ampoule assembly was rapidly removed from the furnace and quenched in an ice bath filled with $\mathrm{NaCl}$.

Upon cooling, the ingot was cut into discs and polished in oil-based diamond suspensions for further analysis. Optical microscopy was utilized with cross-polarized light to visualize cross-sectioned specimens at various magnifications (12.5$1000 \times$ ) using a Leitz Orthoplan optical microscope (Leica Microsystems GmbH, Wetzlar, Germany). Imaging was performed using a Sony DSC-F717 digital camera connected to the microscope through a $\mathrm{C}$-mount adapter.

A crystal suitable for structure determination was identified amongst the small pieces, which broke off one of the cut discs. A series of Omega scans were collected at $150 \mathrm{~K}$ from an untwinned crystal $30 \times 70 \times 70 \mu \mathrm{m}$ using a Bruker APEXII diffractometer (Bruker AXS Inc., Madison, WI) and Mo $K_{\alpha}$ radiation (more details are provided in the Refinement section). Absorption corrections were applied using the multiscan method and the structure refined with SHELXTL.

The EBSD analysis was performed on a polished cross section of the sample using a Bruker e-Flash HR (Bruker AXS Inc., Madison, WI) coupled to a JSM-7001F field-emission gun SEM (JEOL USA, Inc., Peabody, MA). Mapping was performed under $30 \mathrm{kV}$ acceleration voltage at $200 \times$ magnification at $1024 \times 768$ pixel resolution $\left(0.2789 \mathrm{~mm}^{2}\right.$ map size $)$, a 12.9 frames per second average collection rate, a $2.9^{\circ}$ detector tilt angle, and a $70^{\circ}$ sample tilt angle. Data were analyzed using ESPRIT (v1.9) software (Bruker AXS Inc.). Data processing revealed a $92.7 \%$ phase match with $7.3 \%$ of unidentified regions (zero solutions).

The STEM and TEM analyses were performed on an electron-transparent lamella $\left(\sim 5 \times 10 \mu \mathrm{m}^{2}\right)$ prepared via a cross-sectional lift-out technique using a FEI Quanta 3D focused ion beam (FIB). A JEOL ARM 200CF, a cold field emission, aberration probe corrected TEM (JEOL USA, Inc.; Peabody, MA) operated at $200 \mathrm{kV}$ was utilized to examine these samples. Several techniques were used, including SAD in conventional TEM mode, STEM high-angle annular darkfield (HAADF) and annular brightfield (ABF) as well as EELS. The EELS analysis was performed on a Gatan Quantum 965 ER Gatan Image Filter (Gatan Inc., Pleasanton, CA) equipped with fast shutter and dual EELS modules. The EELS spectra and spectroscopic mapping were performed with a convergence angle of $27.5 \mathrm{mrad}$ and a collection angle of $90 \mathrm{mrad}$ using the $\mathrm{Ge} L_{\alpha}$, As $L_{\alpha}$, and $\mathrm{Cd} M_{\alpha}$ lines. Back-
Table 1

Experimental details.

\begin{tabular}{|c|c|}
\hline \multicolumn{2}{|l|}{ Crystal data } \\
\hline Chemical formula & $\mathrm{Cd}_{3} \mathrm{Ge}_{2} \mathrm{As}_{4}$ \\
\hline$M_{\mathrm{r}}$ & 782.06 \\
\hline Crystal system, space group & Trigonal, $R \overline{3}$ \\
\hline Temperature (K) & 150 \\
\hline$a, c(\AA)$ & $7.3748(13), 27.415(5)$ \\
\hline$V\left(\AA^{3}\right)$ & $1291.3(5)$ \\
\hline$Z$ & 6 \\
\hline Radiation type & Мo $K \alpha$ \\
\hline$\mu\left(\mathrm{mm}^{-1}\right)$ & 29.36 \\
\hline Crystal size $(\mathrm{mm})$ & $0.07 \times 0.07 \times 0.03$ \\
\hline \multicolumn{2}{|l|}{ Data collection } \\
\hline Diffractometer & $\begin{array}{l}\text { Bruker APEXII CCD area } \\
\text { detector }\end{array}$ \\
\hline Absorption correction & $\begin{array}{l}\text { Multi-scan (SADABS; Bruker, } \\
\text { 2001) }\end{array}$ \\
\hline$T_{\min }, T_{\max }$ & $0.147,0.414$ \\
\hline $\begin{array}{l}\text { No. of measured, independent and } \\
\text { observed }[I>2 \sigma(I)] \text { reflections }\end{array}$ & $20756,2026,1702$ \\
\hline$R_{\mathrm{int}}$ & 0.062 \\
\hline \multicolumn{2}{|l|}{ Refinement } \\
\hline$R\left[F^{2}>2 \sigma\left(F^{2}\right)\right], w R\left(F^{2}\right), S$ & $0.025,0.049,1.03$ \\
\hline No. of reflections & 2026 \\
\hline No. of parameters & 29 \\
\hline$\Delta \rho_{\max }, \Delta \rho_{\min }\left(\mathrm{e} \AA^{-3}\right)$ & $2.00,-2.18$ \\
\hline
\end{tabular}

Computer programs: APEX2 and SAINT (Bruker, 2012), SHELXTL (Sheldrick, 2008), VESTA (Momma \& Izumi, 2011) and publCIF (Westrip, 2010).

ground subtraction and spectral math were performed with the Gatan Digital Microscopy Suite (v3.0).

\section{Refinement}

Crystal data, data collection and structure refinement details are summarized in Table 1. A suitable crystal for SC-XRD was selected and mounted on a Bruker APEXII diffractometer with a microfocus Mo- $\mathrm{K}_{\alpha} \mathrm{X}$-ray tube and a CCD detector. Data were collected with $0.7^{\circ}$ frame widths in $\omega$ and $20 \mathrm{~s}$ dwell times per frame with the crystal held at $150 \mathrm{~K}$. A total of 2198 frames were collected, and the total exposure time was $12.21 \mathrm{~h}$. The frames were integrated with the SAINT (Bruker, 2012) software package using a narrow-frame algorithm. The integration of the data using a trigonal unit cell yielded a total of 20756 reflections to a maximum $\theta$ angle of $42.35^{\circ}(0.53 \AA$ resolution), of which 2026 were independent (average redundancy 10.245 , completeness $=98.6 \%, R_{\text {int }}=6.18 \%, R_{\text {sig }}=$ $3.19 \%)$ and $1702(84.01 \%)$ were greater than $2 \sigma\left(|F|^{2}\right)$. The final cell constants of $a=7.3748$ (13) $\AA, b=7.3748$ (13) $\AA, c=$ 27.415 (5) $\AA$, and volume = 1291.3 (5) $\AA^{3}$, are based upon the refinement of the $X Y Z$-centroids of 6406 reflections above 20 $\sigma(I)$ with $8.723^{\circ}<2 \theta<82.60^{\circ}$. Data were corrected for absorption effects using the multi-scan method with the $S A D A B S$ software program (Bruker, 2001). The ratio of minimum-to-maximum apparent transmission was 0.476 . The calculated minimum and maximum transmission coefficients (based on crystal size) were 0.2330 and 0.4730 . The structure was solved and refined using the SHELXTL (Sheldrick, 2008) software package, using the space group $R \overline{3}$, with $Z=6$ for the formula unit, $\mathrm{As}_{4} \mathrm{Cd}_{3} \mathrm{Ge}_{2}$ (referred to here as $\mathrm{Cd}_{3} \mathrm{Ge}_{2} \mathrm{As}_{4}$ ). 


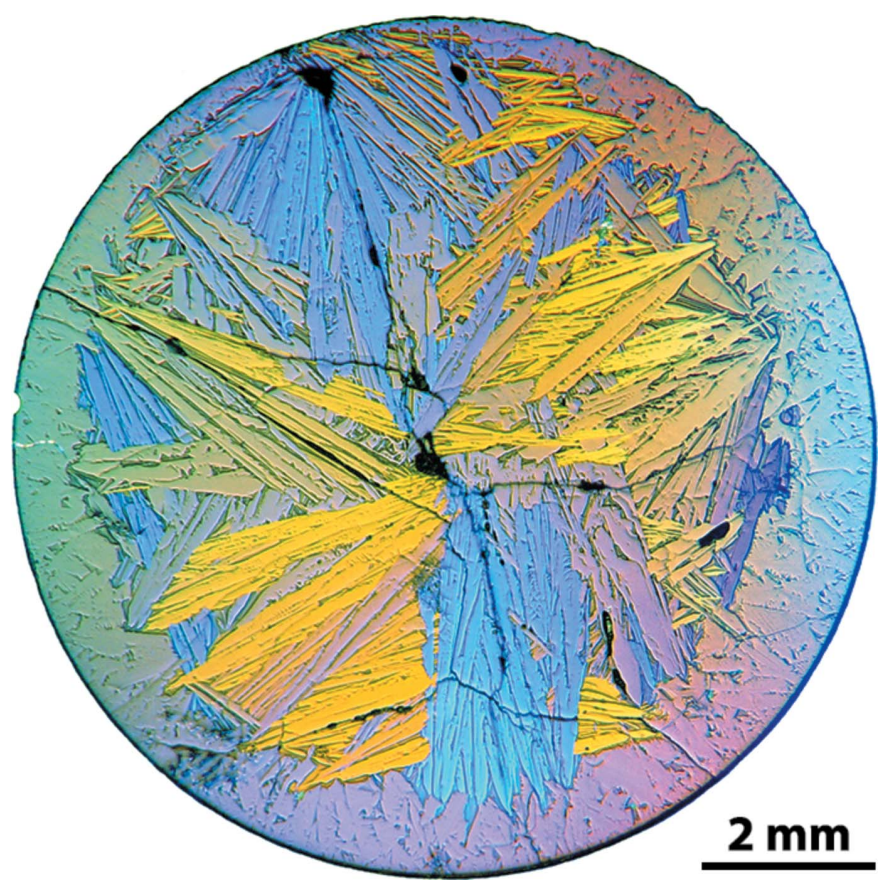

Figure 4

Cross-polarized light optical micrograph of a cross-sectioned sample disc after polishing showing the crystals within the core and the amorphous rim around the perimeter.

The final anisotropic full-matrix least-squares refinement on $F^{2}$ with 29 variables converged at $R_{1}=2.53 \%$, for the observed data and $\mathrm{w} R_{2}=4.91 \%$ for all data. The goodness-of-fit was 1.032. The largest peak in the final difference electron density synthesis was $1.996 \mathrm{e}^{-} \AA^{-3}$ and the largest hole was $-2.180 \mathrm{e}^{-}$ $\AA^{-3}$ with an r.m.s. deviation of $0.324 \mathrm{e}^{-} \AA^{-3}$. On the basis of the final model, the calculated density was $6.034 \mathrm{Mg} \mathrm{m}^{-3}$ and $F(000), 2040 \mathrm{e}^{-}$.
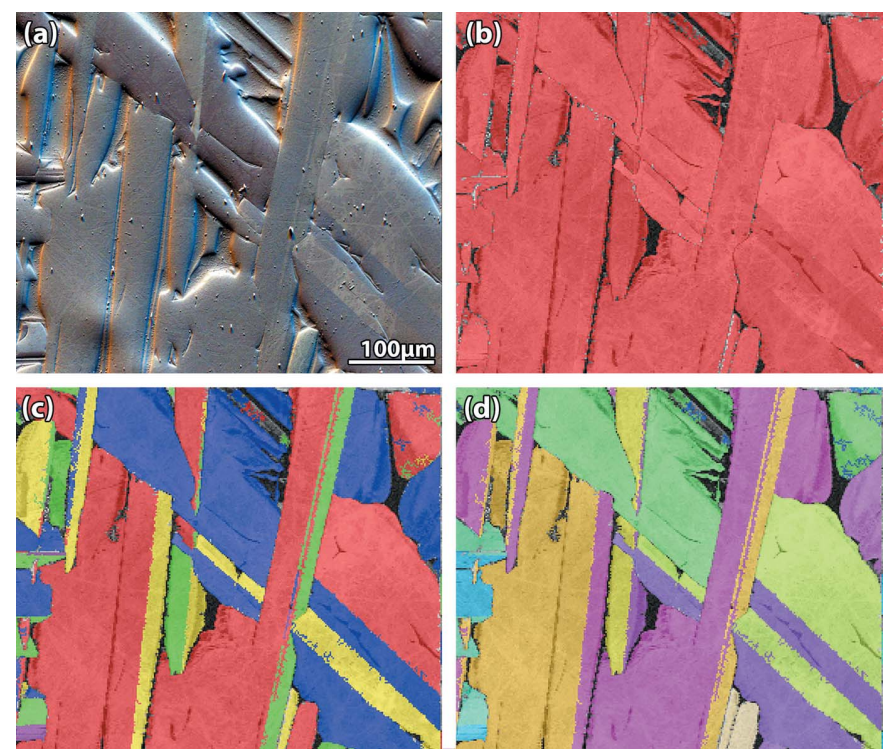

Figure 5

EBSD pattern collage including the (a) Argus image, (b) phase map refined using the crystallographic information file (CIF), (c) grain map, and $(d)$ inverse pole figure (in the $X$-direction) map.

\section{Results and discussion}

Through the progression of samples fabricated to optimize production of the $\mathrm{Cd}_{3} \mathrm{Ge}_{2} \mathrm{As}_{4}$ crystals (Riley et al., 2012), optical microscopy was used to assess macroscopic features and crystal yield. While the crystals and the glassy matrix have similar compositions, the crystals could be separately visualized using cross-polarized light illumination; this provided a technique for broadly assessing the crystallite size. This can be seen in Fig. 4 where the crystallites populate the core of the disc and the amorphous outer layer can be separately visualized.

The EBSD mapping shown in Fig. 5 confirms that the CIF generated from SC-XRD analysis of the $\mathrm{Cd}_{3} \mathrm{Ge}_{2} \mathrm{As}_{4}$ crystal indexed well to the Kikuchi patterns. This data was used to corroborate the SC-XRD data. The orientation maps presented in Fig. $5 c$ demonstrate that the grain sizes can span several hundred micrometers.
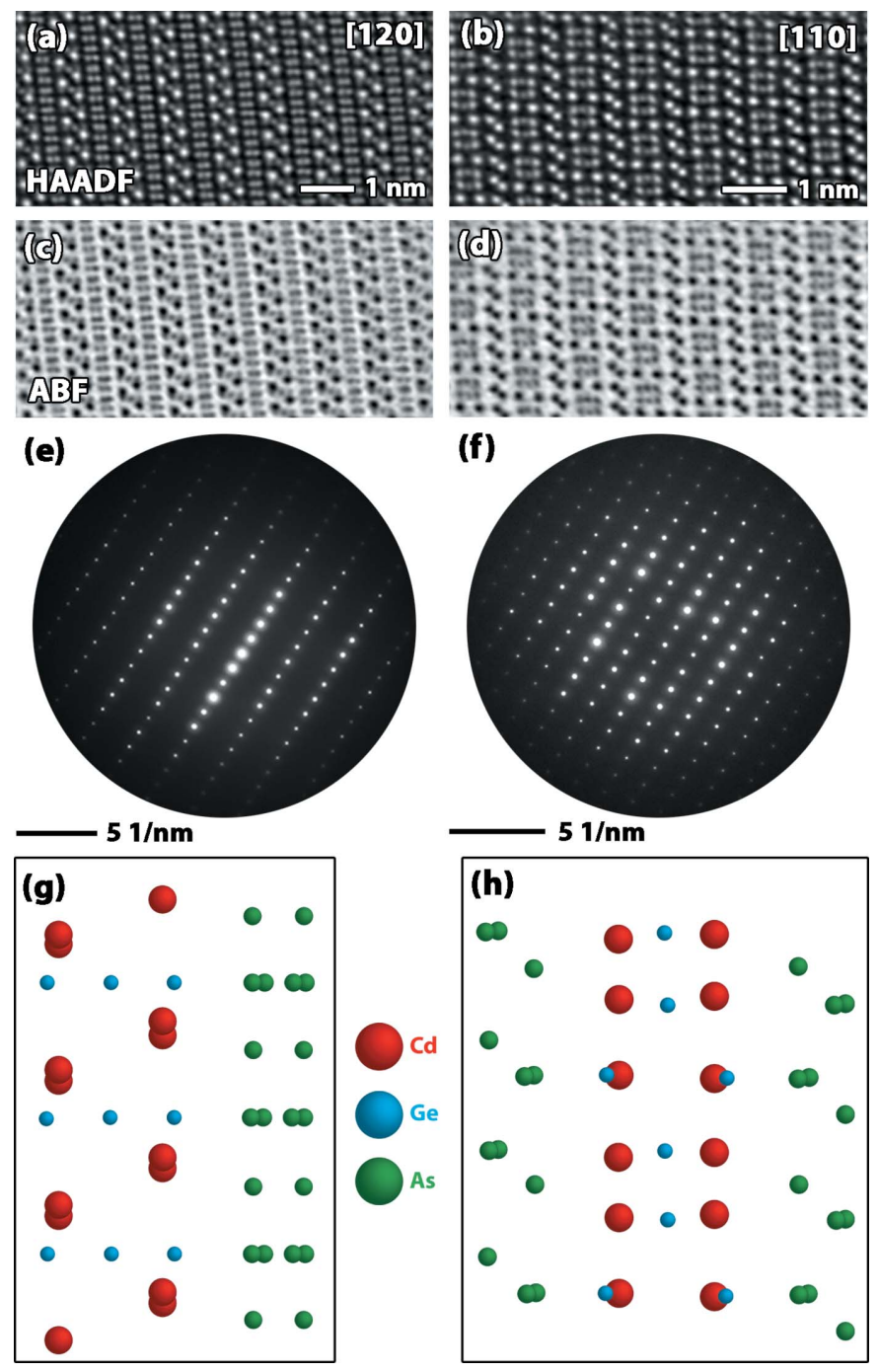

Figure 6

(a)-(d) Atomic-resolution column micrographs in STEM $(a),(b)$ HAADF and $(c),(d)$ ABF imaging modes as well as the $(e),(f)$ selected area diffraction and $(g),(h)$ corresponding atomic identifications for each pole (i.e., [120] on the left and [110] on the right). 
Utilizing both the diffraction patterns in TEM mode and the Kikuchi map in STEM Ronchigram mode, the sample was tilted to obtain low index zone axes in order to better understand the crystallography of the material. Fig. 6 shows HAADF, ABF, and diffraction patterns collected from the $111-$ $20\}$ and $\{21-30\}$ type planes of the trigonal crystal. Ball-andstick models of these orientations (derived from previously mentioned XRD studies) matched extremely well with the atomic column imaging collected in STEM mode. While slight drift in the imaging of the sample during data collection is apparent in the atomic column images, the local ordering could be related to the XRD data. The contrast of the HAADF images was used to corroborate the symmetry and the location of the atoms, but since the predicted structure did suggest overlap of atomic species, using the contrast in the HAADF and ABF images was insufficient to explicitly prove the structure.

Atomic column dual EELS mapping shown in Fig. 7 provided a clearer picture of the chemical location of each of the atoms within the crystal. The $\mathrm{Cd}-M_{\alpha}$ edge, starting at $403.7 \mathrm{eV}$ (see Fig. 8), was utilized to map the location of the Cd elements in both orientations shown in Fig. 6 . In the $\{12-30\}$ orientation, the distinct $\mathrm{Cd}$ positions could be easily mapped without overlap from either the Ge or As. In the $\{11-20\}$ orientation, the $\mathrm{Cd}$ overlapped with the $\mathrm{Ge}$, and hence the signal was slightly obscured, but individual atomic positions could still be observed. The Ge and the As signals were more complicated because of their $L_{\alpha}$ edge onsets at 1217 and $1323 \mathrm{eV}$, respectively. The higher energy edges were more difficult to map because of shorter collection times and low signal-to-noise ratios. Additionally, since the edges are so close in energy, background subtraction and signal integration were

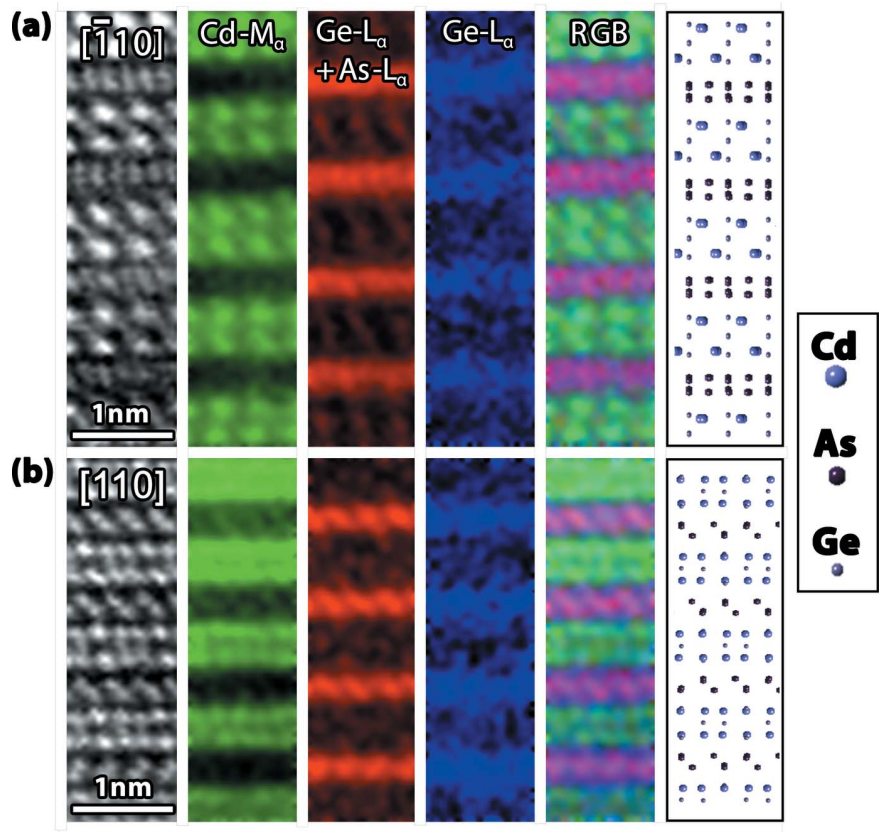

Figure 7

Atomic column EELS maps for two crystallographic poles, i.e., (a) [110] and $(b)$ [110], in the trigonal system to different regions within the crystal (note these are rotated $90^{\circ}$ from the images in Fig. 6).
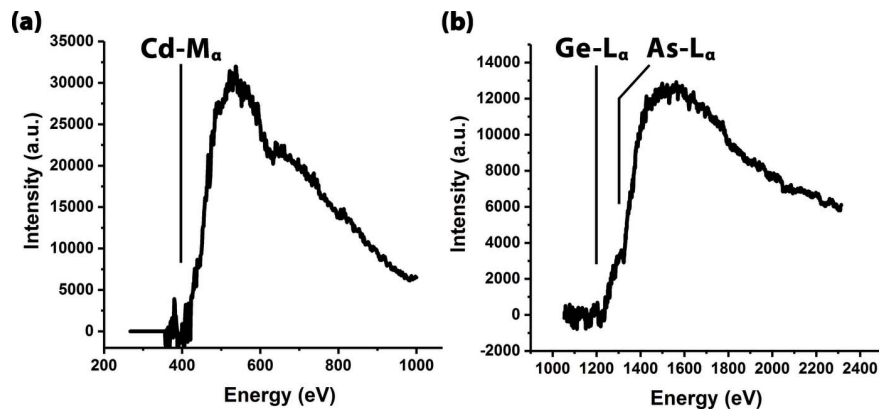

Figure 8

EELS spectra showing the identification of (a) Cd- $M_{\alpha},(b) \mathrm{Ge}-L_{\alpha}$, and $(b)$ As- $L_{\alpha}$ energy lines that were used for elemental identification and mapping.

difficult. Theoretically, the Ge- $L_{\alpha}$ edge could be decoupled from the As- $L_{\alpha}$ edge, but because of the minimal amount of integration before the As- $L_{\alpha}$ edge, the amount of intensity does not provide adequate information for successful deconvolution.

In EELS, the As- $L_{\alpha}$ signal will always be convoluted with the Ge- $L_{\alpha}$ signal, so exact identification of the As versus the Ge proved difficult. Mapping of the Ge- $L_{\alpha}$ edge before the As- $L_{\alpha}$ edge $(\sim 1217-1320 \mathrm{eV})$ provided a map that suggests there are Ge and As substitutions in both orientations. When the As- $L_{\alpha}+\mathrm{Ge}-L_{\alpha}$ edges were utilized for mapping, the signal validated the XRD data in that there were individual layers of As in both orientations. Mapping of the Ge- $L_{\alpha}$ edge showed little $\mathrm{Ge}$ amongst the $\mathrm{Cd}$ layers, but when the $\mathrm{Ge}$ and As signals were used, the atomic positions suggested by XRD and HAADF were expressed. Again, since it is difficult to deconvolve the two signals, atomic column mapping could not be used to definitively identify the positions of the As and Ge atoms within the crystal structure. Difference maps are also provided in Fig. 7 (i.e., RGB mix), which give a good indication of the positions of the elements in relation to one another.

\section{Funding information}

Funding for this research was provided by: Pacific Northwest National Laboratory (PNNL), which is operated for the US Department of Energy by Battelle under Contract DE-AC0576RL01830.

\section{References}

Borshchevskii, A. S., Goryunova, N. A., Kesamanly, F. P. \& Nasledov, D. N. (1967). Phys. Status Solidi B, 21, 9-55.

Borshchevskii, A. S. \& Roenkov, N. D. (1969). Russ. J. Inorg. Chem. 14, 1183-1186.

Boyd, G. D., Buehler, E., Storz, F. G. \& Wernick, J. H. (1972). IEEE J. Quantum Electron. 8, 419-426.

Bruker (2001). SADABS. Bruker AXS Inc., Madison, Wisconsin, USA.

Bruker (2012). SAINT. Bruker AXS Inc., Madison, Wisconsin, USA. Byer, R. L. (1975). Optical parametric oscillators, in Quantum Electronics: A Treatise, edited by H. Rabin and C. L. Tang, pp. 587702. New York: Academic Press.

Byer, R. L., Kildal, H. \& Feigelson, R. S. (1971). Appl. Phys. Lett. 19, 237-240. 
Hong, K. S., Berta, Y. \& Speyer, R. F. (1990). J. Am. Ceram. Soc. 73, 1351-1359.

Iseler, G. W., Kildal, H. \& Menyuk, N. (1978). J. Electron. Mater. 7, 737-755.

Johnson, B. R., Riley, B. J., Sundaram, S. K., Crum, J. V., Henager, C. H. Jr, Zhang, Y., Shutthanandan, V., Seifert, C. E., Van Ginhoven, R. M., Chamberlin, C. E., Rockett, A. A., Hebert, D. N. \& Aquino, A. R. (2009). J. Amer. Ceram. Soc. 92, 1236-1243.

Kildal, H. (1972). PhD thesis, Stanford University.

Mikkelsen, J. C. Jr \& Hong, H. Y.-P. (1974). Mater. Res. Bull. 9, 12091218.

Momma, K. \& Izumi, F. (2011). J. Appl. Cryst. 44, 1272-1276.

Pamplin, B. R. \& Feigelson, R. S. (1979). Mater. Res. Bull. 14, $263-$ 266.
Riley, B. J., Johnson, B. R., Crum, J. V. \& Thompson, M. R. (2012). J. Am. Ceram. Soc. 95, 2161-2168.

Schunemann, P. G. \& Pollak, T. M. (1998). Mater. Res. Bull. 23, 23-27. Sharma, S., Hong, K. S. \& Speyer, R. F. (1989). J. Mater. Sci. Lett. 8, 950-954.

Shay, J. L. \& Wernick, J. H. (1975). Ternary Chalcopyrite Semiconductors: Growth, Electronic Properties, and Applications. New York: Pergamon Press.

Sheldrick, G. M. (2008). Acta Cryst. A64, 112-122.

Speyer, R. F., Berta, Y., Hong, K. \& Risbud, S. H. (1989). J. NonCryst. Solids, 110, 235-248.

Zawilski, K. T., Schunemann, P. G. \& Pollak, T. M. (2008). J. Cryst. Growth, 310, 1897-1903.

Westrip, S. P. (2010). J. Appl. Cryst. 43, 920-925. 


\section{supporting information}

Acta Cryst. (2019). E75, 1291-1296 [https://doi.org/10.1107/S2056989019010636]

\section{Crystal structure and chemistry of tricadmium digermanium tetraarsenide, $\mathrm{Cd}_{3} \mathrm{Ge}_{2} \mathrm{As}_{4}$}

Michael R. Thompson, Brian J. Riley, Mark E. Bowden, Matthew J. Olszta, Danny J. Edwards, Jarrod V. Crum, Bradley R. Johnson and Saehwa Chong

Computing details

Data collection: APEX2 (Bruker, 2012); cell refinement: SHELXTL (Sheldrick, 2008); data reduction: SAINT (Bruker, 2012); program(s) used to solve structure: SHELXTL (Sheldrick, 2008); program(s) used to refine structure: SHELXTL (Sheldrick, 2008); molecular graphics: VESTA (Momma \& Izumi, 2011); software used to prepare material for publication: publCIF (Westrip, 2010).

Tricadmium digermanium tetraarsenide

Crystal data

$\mathrm{Cd}_{3} \mathrm{Ge}_{2} \mathrm{As}_{4}$

$M_{r}=782.06$

Trigonal, $R \overline{3}$

Hall symbol: $-\mathrm{R} 3$

$a=7.3748(13) \AA$

$c=27.415(5) \AA$

$V=1291.3(5) \AA^{3}$

$Z=6$

$F(000)=2040$

Data collection

Bruker APEXII CCD area detector diffractometer

$\omega$ and $\varphi$ scans

Absorption correction: multi-scan

(SADABS; Bruker, 2001)

$T_{\min }=0.147, T_{\max }=0.414$

20756 measured reflections

\section{Refinement}

Refinement on $F^{2}$

Least-squares matrix: full

$R\left[F^{2}>2 \sigma\left(F^{2}\right)\right]=0.025$

$w R\left(F^{2}\right)=0.049$

$S=1.03$

2026 reflections

29 parameters

0 restraints

Primary atom site location: structure-invariant direct methods
$D_{\mathrm{x}}=6.034 \mathrm{Mg} \mathrm{m}^{-3}$

Mo $K \alpha$ radiation, $\lambda=0.71073 \AA$

Cell parameters from 20756 reflections

$\theta=2.2-42.4^{\circ}$

$\mu=29.36 \mathrm{~mm}^{-1}$

$T=150 \mathrm{~K}$

Triangular prism, black

$0.07 \times 0.07 \times 0.03 \mathrm{~mm}$

2026 independent reflections

1702 reflections with $I>2 \sigma(I)$

$R_{\text {int }}=0.062$

$\theta_{\text {max }}=42.4^{\circ}, \theta_{\min }=2.2^{\circ}$

$h=-13 \rightarrow 13$

$k=-13 \rightarrow 13$

$l=-51 \rightarrow 51$

$w=1 /\left[\sigma^{2}\left(F_{\mathrm{o}}{ }^{2}\right)+(0.0102 P)^{2}+16.7635 P\right]$

where $P=\left(F_{\mathrm{o}}^{2}+2 F_{\mathrm{c}}^{2}\right) / 3$

$(\Delta / \sigma)_{\max }=0.001$

$\Delta \rho_{\max }=2.00 \mathrm{e} \AA^{-3}$

$\Delta \rho_{\min }=-2.18$ e $\AA^{-3}$

Extinction correction: SHELXL2016

(Sheldrick, 2015),

$\mathrm{Fc}^{*}=\mathrm{kFc}\left[1+0.001 \mathrm{xFc}^{2} \lambda^{3} / \sin (2 \theta)\right]^{-1 / 4}$

Extinction coefficient: 0.00068 (3) 


\section{Special details}

Geometry. All esds (except the esd in the dihedral angle between two 1.s. planes) are estimated using the full covariance matrix. The cell esds are taken into account individually in the estimation of esds in distances, angles and torsion angles; correlations between esds in cell parameters are only used when they are defined by crystal symmetry. An approximate (isotropic) treatment of cell esds is used for estimating esds involving l.s. planes.

Refinement. Reflections were merged by SHELXL according to the crystal class for the calculation of statistics and refinement.

_reflns_Friedel_fraction is defined as the number of unique Friedel pairs measured divided by the number that would be possible theoretically, ignoring centric projections and systematic absences.

Fractional atomic coordinates and isotropic or equivalent isotropic displacement parameters $\left(\AA^{2}\right)$

\begin{tabular}{lllll}
\hline & $x$ & $y$ & $z$ & $U_{\text {iso }} * U_{\text {eq }}$ \\
\hline Cd1 & $0.63686(3)$ & $0.64317(3)$ & $0.05011(2)$ & $0.01073(5)$ \\
As1 & $0.49777(4)$ & $0.50674(4)$ & $0.14283(2)$ & $0.00577(5)$ \\
As2 & 1.000000 & 1.000000 & $0.15184(2)$ & $0.00553(7)$ \\
Ge1 & 1.000000 & 1.000000 & $0.06367(2)$ & $0.00604(8)$ \\
Ge2 & 0.666667 & 0.333333 & $0.00242(2)$ & $0.00535(7)$ \\
\hline
\end{tabular}

Atomic displacement parameters $\left(\AA^{2}\right)$

\begin{tabular}{lllllll}
\hline & $U^{11}$ & $U^{22}$ & $U^{33}$ & $U^{12}$ & $U^{13}$ & $U^{23}$ \\
\hline Cd1 & $0.01246(8)$ & $0.01108(8)$ & $0.00932(7)$ & $0.00638(7)$ & $-0.00329(6)$ & $-0.00271(6)$ \\
As1 & $0.00541(9)$ & $0.00536(10)$ & $0.00664(9)$ & $0.00277(8)$ & $-0.00009(7)$ & $0.00023(7)$ \\
As2 & $0.00523(10)$ & $0.00523(10)$ & $0.00615(16)$ & $0.00261(5)$ & 0.000 & 0.000 \\
Ge1 & $0.00695(11)$ & $0.00695(11)$ & $0.00422(16)$ & $0.00348(5)$ & 0.000 & 0.000 \\
Ge2 & $0.00442(10)$ & $0.00442(10)$ & $0.00722(17)$ & $0.00221(5)$ & 0.000 & 0.000 \\
\hline
\end{tabular}

Geometric parameters $\left(\AA,{ }^{\circ}\right)$

\begin{tabular}{llll}
\hline $\mathrm{Cd} 1-\mathrm{Ge} 1$ & $2.6810(5)$ & $\mathrm{As} 1-\mathrm{As} 2^{\mathrm{ii}}$ & $2.4296(5)$ \\
$\mathrm{Cd} 1-\mathrm{Ge} 2$ & $2.7352(5)$ & $\mathrm{As} 1-\mathrm{As} 1^{\mathrm{iii}}$ & $2.4496(5)$ \\
$\mathrm{Cd} 1-\mathrm{As} 1$ & $2.7374(5)$ & $\mathrm{As} 1-\mathrm{As} 1^{\mathrm{iv}}$ & $2.4496(5)$ \\
$\mathrm{Cd} 1-\mathrm{Ge} 2^{\mathrm{i}}$ & $2.7390(5)$ & $\mathrm{As} 2-\mathrm{Ge} 1$ & \\
$\mathrm{Cd} 1-\mathrm{Cd} 1^{\mathrm{i}}$ & $3.4379(6)$ & & \\
& & & \\
$\mathrm{Ge} 1-\mathrm{Cd} 1-\mathrm{Ge} 2$ & $115.352(9)$ & $\mathrm{As} 2-\mathrm{Ge} 1-\mathrm{Cd} 1$ & $97.973(11)$ \\
$\mathrm{Ge} 1-\mathrm{Cd} 1-\mathrm{As} 1$ & $103.815(15)$ & $\mathrm{As} 2-\mathrm{Ge} 1-\mathrm{Cd} 1^{\mathrm{vi}}$ & $118.108(5)$ \\
$\mathrm{Ge} 2-\mathrm{Cd} 1-\mathrm{As} 1$ & $107.978(14)$ & $\mathrm{Cd} 1-\mathrm{Ge} 1-\mathrm{Cd} 1^{\mathrm{vi}}$ & $97.973(11)$ \\
$\mathrm{Ge} 1-\mathrm{Cd} 1-\mathrm{Ge} 2^{\mathrm{i}}$ & $117.239(9)$ & $\mathrm{As} 2-\mathrm{Ge} 1-\mathrm{Cd} 1^{\mathrm{vi}}$ & $118.109(5)$ \\
$\mathrm{Ge} 2-\mathrm{Cd} 1-\mathrm{Ge} 2^{\mathrm{i}}$ & $102.189(11)$ & $\mathrm{Cd} 1-\mathrm{Ge} 1-\mathrm{Cd} 1^{\mathrm{vii}}$ & $118.108(5)$ \\
$\mathrm{As} 1-\mathrm{Cd} 1-\mathrm{Ge} 2^{\mathrm{i}}$ & $110.095(15)$ & $\mathrm{Cd} 1^{\mathrm{vi}}-\mathrm{Ge} 1-\mathrm{Cd} 1^{\mathrm{vi}}$ & $99.051(15)$ \\
$\mathrm{Ge} 1-\mathrm{Cd} 1-\mathrm{Cd} 1^{\mathrm{i}}$ & $134.854(15)$ & $\mathrm{Cd} 1^{\mathrm{vii}}-\mathrm{Ge} 2-\mathrm{Cd} 1^{\mathrm{ix}}$ & $99.050(14)$ \\
$\mathrm{Ge} 2-\mathrm{Cd} 1-\mathrm{Cd} 1^{\mathrm{i}}$ & $51.144(9)$ & $\mathrm{Cd} 1^{\mathrm{viii}}-\mathrm{Ge} 2-\mathrm{Cd} 1$ & $99.050(14)$ \\
$\mathrm{As} 1-\mathrm{Cd} 1-\mathrm{Cd} 1^{\mathrm{i}}$ & $121.283(16)$ & $\mathrm{Cd} 1^{\mathrm{ix}}-\mathrm{Ge} 2-\mathrm{Cd} 1$ & $88.526(12)$ \\
$\mathrm{Ge} 2^{\mathrm{i}}-\mathrm{Cd} 1-\mathrm{Cd} 1^{\mathrm{i}}$ & $51.045(9)$ & $\mathrm{Cd} 1^{\mathrm{viii}}-\mathrm{Ge} 2-\mathrm{Cd} 1^{\mathrm{x}}$ & $77.810(11)$ \\
$\mathrm{As} 2^{\mathrm{ii}}-\mathrm{As} 1-\mathrm{As} 1^{\mathrm{iii}}$ & $97.897(17)$ & $\mathrm{Cd} 1^{\mathrm{ix}}-\mathrm{Ge} 2-\mathrm{Cd} 1^{\mathrm{x}}$ & $172.207(10)$ \\
$\mathrm{As} 2^{\mathrm{ii}}-\mathrm{As} 1-\mathrm{As} 1^{\mathrm{iv}}$ & $99.093(17)$ & $\mathrm{Cd} 1-\mathrm{Ge} 2-\mathrm{Cd} 1^{\mathrm{x}}$ & $77.810(11)$ \\
$\mathrm{As} 1^{\mathrm{iii}}-\mathrm{As} 1-\mathrm{As} 1^{\mathrm{iv}}$ & $94.181(17)$ & $\mathrm{Cd} 1^{\mathrm{viii}}-\mathrm{Ge} 2-\mathrm{Cd} 1^{\mathrm{xi}}$ &
\end{tabular}


supporting information

$\begin{array}{llll}\mathrm{As} 2^{\mathrm{ii}}-\mathrm{As} 1-\mathrm{Cd} 1 & 113.706(15) & \mathrm{Cd} 1^{\mathrm{ix}}-\mathrm{Ge} 2-\mathrm{Cd} 1^{\mathrm{xi}} & 172.207(10) \\ \mathrm{As} 1^{\mathrm{ii}}-\mathrm{As} 1-\mathrm{Cd} 1 & 140.455(14) & \mathrm{Cd} 1-\mathrm{Ge} 2-\mathrm{Cd} 1^{\mathrm{xi}} & 88.526(11) \\ \mathrm{As} 1^{\mathrm{iv}}-\mathrm{As} 1-\mathrm{Cd} 1 & 103.154(16) & \mathrm{Cd} 1^{\mathrm{x}}-\mathrm{Ge} 2-\mathrm{Cd} 1^{\mathrm{xi}} & 94.898(15) \\ \mathrm{Ge} 1-\mathrm{As} 2-\mathrm{As} 1^{\mathrm{ii}} & 115.864(13) & \mathrm{Cd} 1^{\mathrm{viii}}-\mathrm{Ge} 2-\mathrm{Cd} 1^{\mathrm{i}} & 172.207(10) \\ \mathrm{Ge} 1-\mathrm{As} 2-\mathrm{As} 1^{\mathrm{v}} & 115.864(13) & \mathrm{Cd} 1^{\mathrm{i}}-\mathrm{Ge} 2-\mathrm{Cd} 1^{\mathrm{i}} & 88.526(11) \\ \mathrm{As} 1^{\mathrm{ii}}-\mathrm{As} 2-\mathrm{As} 1^{\mathrm{v}} & 102.389(15) & \mathrm{Cd} 1-\mathrm{Ge} 2-\mathrm{Cd} 1^{\mathrm{i}} & 77.810(11) \\ \mathrm{Ge} 1-\mathrm{As} 2-\mathrm{As} 1^{\mathrm{iv}} & 115.864(13) & \mathrm{Cd} 1^{\mathrm{x}}-\mathrm{Ge} 2-\mathrm{Cd} 1^{\mathrm{i}} & 94.898(15) \\ \mathrm{As} 1^{\mathrm{ii}}-\mathrm{As} 2-\mathrm{As} 1^{\mathrm{iv}} & 102.389(15) & \mathrm{Cd} 1^{\mathrm{xi}}-\mathrm{Ge} 2-\mathrm{Cd} 1^{\mathrm{i}} & 94.898(15) \\ \mathrm{As} 1^{\mathrm{v}}-\mathrm{As} 2-\mathrm{As} 1^{\mathrm{iv}} & 102.388(15) & & \end{array}$

Symmetry codes: (i) $-x+1,-y+1,-z$; (ii) $-x+5 / 3,-y+4 / 3,-z+1 / 3$; (iii) $y-1 / 3,-x+y+1 / 3,-z+1 / 3$; (iv) $x-y+2 / 3, x+1 / 3,-z+1 / 3$; (v) $y+2 / 3,-x+y+4 / 3,-z+1 / 3$; (vi) $-y+2, x-y+1, z$; (vii) $-x+y+1,-x+2, z$; (viii) $-x+y+1,-x+1, z$; (ix) $-y+1, x-y, z$; (x) $y,-x+y,-z$; (xi) $x-y+1, x,-z$. 